\title{
Automated monitoring of delamination factor during up (conventional) and down (climb) milling of melamine-faced MDF using image processing methods
}

\author{
Katarzyna Śmietańska ${ }^{1}$ (D) P Piotr Podziewski ${ }^{1}$ D $\cdot$ Marcin Bator $^{2}$ (D) - Jarosław Górski ${ }^{1}$ (D)
}

Received: 27 August 2019 / Published online: 11 March 2020

(c) The Author(s) 2020

\begin{abstract}
The main goal of this paper was to examine whether image processing can be an effective tool in automatic quality control systems for furniture manufacturing, at least in cases where delamination is a key problem. Image processing turned out to be a very effective way of delamination factor monitoring. Moreover, the research analyzed the quality effect of up or down milling of melamine-faced MDF. The delamination factor increased significantly with increasing tool wear. However, the increase was not very regular. The experimental data showed that up milling had a significant advantage over down milling.
\end{abstract}

\section{Introduction}

Image processing is becoming an increasingly effective measurement technique useful to automatically ensure whether different types of wood products conform to set specifications or not (e.g., Laszewicz et al. 2013; Kurek et al. 2017). Traditional methods of quality control (e.g., subjective visual inspection) are usually slow, expensive, and prone to human error and bias. During melamine-faced MDF machining, the main problem in terms of quality is delamination. Objective delamination monitoring requires the adoption of some kind of delamination factor. This is not a new issue. For example, Lemaster et al. (2000) determined the average number of chips in $25 \mathrm{~mm}$ sections. Szwajka and Trzepieciński (2017) used the quotient between the surface area of the delaminated zone and the length of the cut.

The main purpose of this paper was to show that image processing can be used in automatic quality control systems for furniture manufacturing. In addition, it was analyzed whether up or down milling of melamine-faced MDF is more beneficial from the quality point of view.

Katarzyna Śmietańska

katarzyna_laszewicz@sggw.pl

1 Faculty of Wood Technology, Warsaw University of Life Sciences, 166 Nowoursynowska St, 02-787 Warsaw, Poland

2 Faculty of Applied Informatics and Mathematics, Warsaw University of Life Sciences, 166 Nowoursynowska St, 02-787 Warsaw, Poland

\section{Materials and methods}

The research was carried out using a standard CNC router, one knife cutter head ( $40 \mathrm{~mm}$ in diameter) and ten exchangeable carbide knives. The experimental workpieces (made of commercial, 16-mm-thick, white melamine-faced MDF) were samples measuring $160 \times 100 \mathrm{~mm}^{2}$, with a groove, 5 $\mathrm{mm}$ deep and $40 \mathrm{~mm}$ wide, milled in each of them. The cutting parameters were a spindle speed of $18000 \mathrm{rpm}$ and feed rate of $2.7 \mathrm{~m} / \mathrm{min}$. All the knives were gradually worn in a way that reflected normal exploitation in real industrial conditions, i.e., the machining of various wood-based materials. At some intervals, this exploitation was interrupted in order to measure the flank wear (VB) using a microscope (Mitutoyo TM-500). Next, the knife was used in the experimental setup to groove in experimental workpieces. This way, nine series of experimental workpieces were grooved using each of the ten knives, with five workpieces per each series. The delamination factor was calculated for each experimental workpiece (separately for up and down milling) as the quotient between the surface area of the delaminated zone and the length of the groove. Image analysis was used to find out the aforementioned surface area. The algorithm was as follows:

1 Scanning a sample

2 Taking two sub-images (each presenting one edge of cutting)

3 Classifying pixels as inner or outer for each sub-image 
4 Computing an expected (theoretic) borderline between them

5 Localizing the edge of cutting

6 Calculating a geometric integral as the area of delamination.

The first step was the scanning (600 dpi) of the samples using a standard office scanner. For a better understanding of the next step (detection of the irregular border of the delamination zone), one should remember that the value of a pixel (the smallest element of digital picture) is a mean value of the light. The consequence is that pixels located on the border of the delamination zone had values that range between the value of pixels of two different areas (white melamine and raw MDF). A white melamine (pixels outside the delamination zone) was not equal in value to a "white" color, but more importantly, it was also uneven - the values were slightly different for each pixel. The raw MDF (pixels inside the delamination zone) was even more uneven in terms of value. Fortunately, the

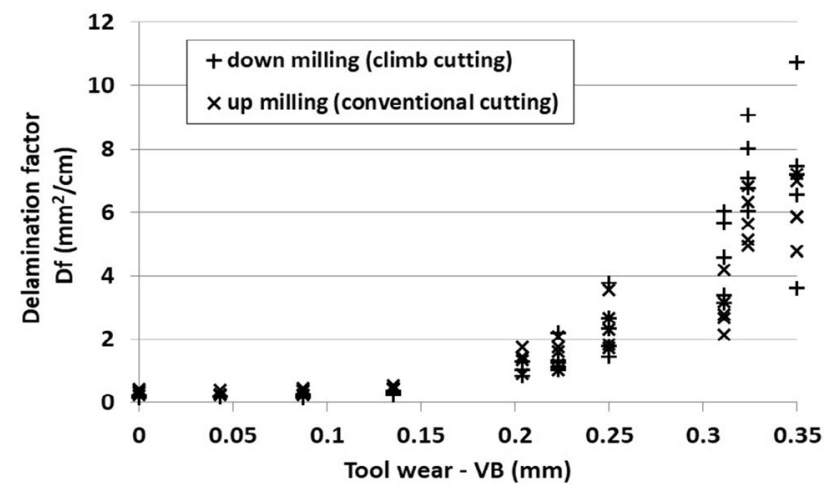

Fig. 1 Effect of tool wear on delamination factor observed for knife no. 5 inner material was visibly darker than the outer one. This knowledge allowed finding a threshold value that worked properly for all of the analyzed images. It is worth emphasizing that sample scanning, scan archiving, file analysis and creation of the output files (reports) were all automatic procedures. The only non-automated activity was the manual transfer of workpieces from the $\mathrm{CNC}$ router to the scanner.

\section{Results and discussion}

Exemplary results of delamination factor monitoring are shown in Fig. 1. Each marker (in this case, a plus sign and $\mathrm{x})$ in these graphs represents the average delamination factor value calculated for one groove edge. The delamination factor increased significantly with increasing tool wear. However, the increase was not very regular.

Initially, the general correlation between delamination factor observed for the up and down milling was tested. The strong positive correlation $\left(\mathrm{R}^{2}=0.88\right)$ suggests that the cutting mode did not have a statistically significant impact on the machining quality. On the other hand, though, it turned out that for small $(0 \leq \mathrm{VB}<0.1 \mathrm{~mm})$ and moderate $(0.1 \leq \mathrm{VB}<0.15 \mathrm{~mm})$ tool wear the conventional cutting was much more favorable than climb cutting (Fig. 2).

It was a statistically significant effect (p-value $<0.01)$. This fact confirms the conclusion by Lemaster et al. (2000) for melamine-coated particleboard routing. On the other hand, the climb cutting (instead of conventional cutting) was definitely recommended by Davim (2013) and Darmawan et al. (2018), who analyzed raw MDF and pine wood (respectively) machining quality.
Fig. 2 Effect of cutting mode (conventional vs. climb) on the mean values of delamination factor for different tool wear ranges (the range $0.25 \leq \mathrm{VB}<0.3$ has been skipped due to the accidental gap in experimental data)

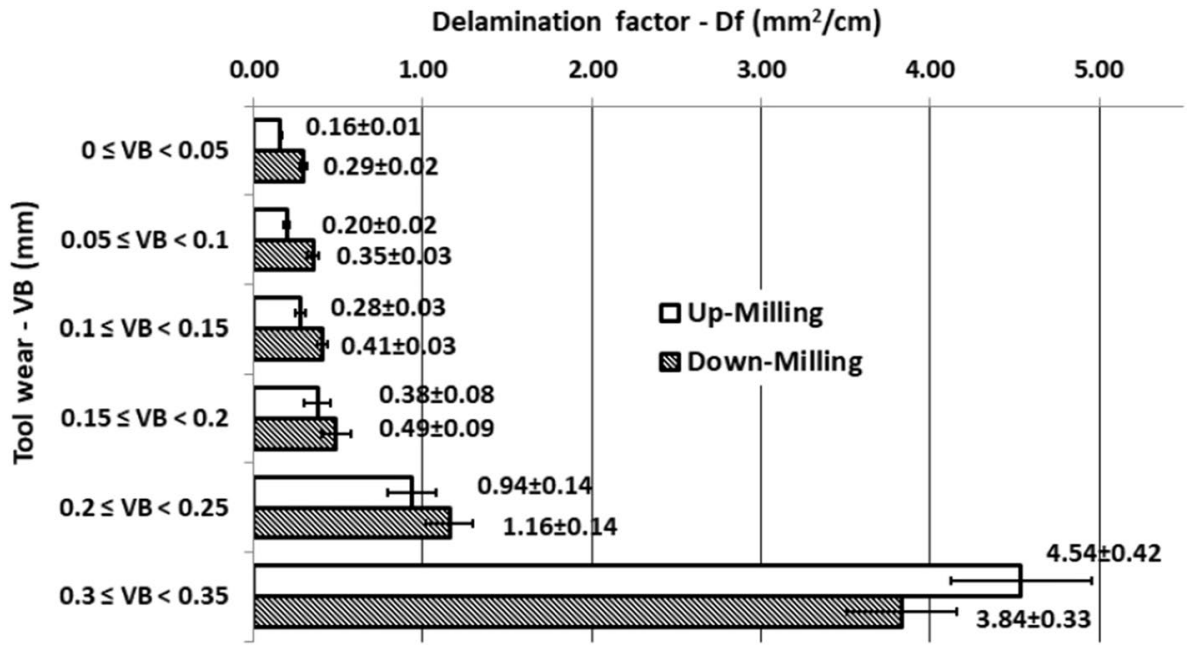




\section{Conclusion}

Image processing turned out to be a very effective way of delamination factor monitoring. For small (VB $<0.1 \mathrm{~mm}$ ) and moderate $(0.1 \leq \mathrm{VB}<0.15 \mathrm{~mm})$ tool wear, up milling was much more favorable than down milling (from the quality point of view). For more advanced tool wear, there was no statistically significant difference between conventional and climb milling.

Acknowledgements The authors would like to thank to Karol Szymanowski and Paweł Czarniak who belonged to the machine-tool operator team.

Open Access This article is licensed under a Creative Commons Attribution 4.0 International License, which permits use, sharing, adaptation, distribution and reproduction in any medium or format, as long as you give appropriate credit to the original author(s) and the source, provide a link to the Creative Commons licence, and indicate if changes were made. The images or other third party material in this article are included in the article's Creative Commons licence, unless indicated otherwise in a credit line to the material. If material is not included in the article's Creative Commons licence and your intended use is not permitted by statutory regulation or exceeds the permitted use, you will need to obtain permission directly from the copyright holder. To view a copy of this licence, visit http://creativecommons.org/licenses/by/4.0/.

\section{References}

Darmawan W, Azhari M, Rahayu IS, Nandika D, Dumasari L, Malela I, Nishio S (2018) The chips generated during up-milling and downmilling of pine wood by helical router bits. J Indian Acad Wood Sci 15(2):172-180. https://doi.org/10.1007/s13196-018-0223-4

Davim P (2013) Wood machining. John Wiley and Sons, New York

Kurek J, Świderski B, Jegorowa A, Kruk M, Osowski S (2017) Deep learning in assessment of drill condition on the basis of images of drilled holes. In: Eighth International Conference on Graphic and Image Processing (ICGIP 016), Tokyo, Japan, pp 1-7.

Laszewicz K, Górski J, Wilkowski J (2013) Long-term accuracy of MDF milling process-development of adaptive control system corresponding to progression of tool wear. Eur J Wood Prod 71(3):383-385. https://doi.org/10.1007/s00107-013-0679-2

Lemaster RL, Lu L, Jackson S (2000) The use of process monitoring techniques on a CNC wood router. Part 2. Use of vibration accelerometer to monitor tool wear and workpiece quality. For Prod J 50(9):59-64

Szwajka K, Trzepieciński T (2017) The influence of machining parameters and tool wear on the delamination process during milling of melamine-faced chipboard. Drewno 60: 118-131. https://doi. org/10.12841/wood.1644-3985.189.09

Publisher's Note Springer Nature remains neutral with regard to jurisdictional claims in published maps and institutional affiliations. 